of Biochemistry, Kings College Hospital, London, UK; ${ }^{3}$ Department of Gastroenterology, Imperial College, St Mary's Hospital, London, UK

Introduction FGF19 is a polypeptide hormone produced in the ileum which inhibits hepatic synthesis of bile acid and is thought to have roles in regulation of bile acid pool size and in clinical conditions of diarrhoea. Fasting serum levels of FGF19 are reduced in patients with Crohn's disease (CD) involving the ileum and also in patients with $\mathrm{CD}$ and ileal resections (IR). Aims: To investigate the relationship between serum FGF19 and disease activity in CD and length of ileal resection.

Methods Blood samples were taken prospectively from patients after an overnight fast in 40 patients with Crohn's disease (24 non resected and 16 with previous IR), 19 healthy controls and 75 disease controls with SeHCAT negative chronic idiopathic diarrhoea. In 9 IR patients clinical records were available to establish the precise length of ileum resected. Disease activity was assessed by Harvey-Bradshaw Index (HBI). Diarrhoea was defined as stool frequency $\geq 3$, Bristol stool chart $\geq 6$. Serum FGF19 was measured by ELISA and data are expressed as medians and ranges. Nonparametric statistical tests (Mann-Whitney and Spearman rank correlations) were used.

Results Median levels of FGF19 were significantly lower in patients with non-resected CD $(114 \mathrm{pg} / \mathrm{ml}, 3-339)$ compared to healthy controls $(231 \mathrm{pg} / \mathrm{ml}, 74-655, \mathrm{p}=0.002$ and 0.005 respectively). Patients with previous IR $(71 \mathrm{pg} / \mathrm{ml}, 17-152)$ had significantly lower levels than non-resected $C D(p=0.02)$. Out of 15 patients with non resected $\mathrm{CD}$ with ileal or ileo-colonic disease, eight had active disease $(\mathrm{HBI}>4)$ and had further radiological or endoscopic assessment of the ileum: four with symptomatic strictures had significantly higher FGF19 levels (328 pg/ml, 178-339) compared to the inactive patients $(118 \mathrm{pg} / \mathrm{ml}, 46-256, \mathrm{p}=0.04)$. Conversely, four with non-obstructive ileal inflammation had significantly lower FGF19 levels $(33 \mathrm{pg} / \mathrm{ml}, 3-59)$ than inactive patients $(p=0.01)$ and this group had the lowest observed levels of FGF19. Six non resected CD with diarrhoea had significantly lower levels of FGF19 (86 pg/ $\mathrm{ml}, 30-169)$ compared to the diarrhoea controls $(246 \mathrm{pg} / \mathrm{ml}$, $72-1000, p=<0.0001)$. In nine IR patients an inverse correlation between FGF19 levels and resection length was observed $(r=-0.81$, p 0.01).

Conclusion Fasting serum levels of FGF19 are significantly reduced by IR or non obstructive ileal inflammation. Symptoms of diarrhoea in CD are associated with low levels of FGF19 and an inverse correlation is found between FGF19 and the length of previous ileal resections.

Competing interests None declared.

\section{OC-081 GENETIC POLYMORPHISMS AND PATTERNS OF FGF19 RESPONSE TO MEALS IN PRIMARY BILE ACID DIARRHOEA}

doi:10.1136/gutjnl-2012-302514a.81

${ }^{1} \mathrm{I}$ Johnston, ${ }^{*}{ }^{1} \mathrm{~S} S \mathrm{~S}$ Pattni, ${ }^{1} \mathrm{~J}$ Lin, ${ }^{2} \mathrm{~T}$ Dew, ${ }^{3} \mathrm{P} \mathrm{H}$ Dixon, ${ }^{1} \mathrm{~J} \mathrm{R}$ Walters. ${ }^{1}$ Department of Gastroenterology and Hepatology, Imperial College London, London, UK; ${ }^{2}$ Department of Clinical Chemistry, Kings College Hospital, NHS Foundation Trust, UK; ${ }^{3}$ Department of Surgery and Cancer, Imperial College London, London, UK

Introduction Primary bile acid diarrhoea (PBAD) is associated with low median serum fibroblast growth factor 19 (FGF19) levels. Our group has suggested that $\mathrm{PBAD}$ results from impaired negative feedback by FGF19 on the enzyme CYP7A1, leading to over production of bile acids, which spill over into the colon leading to diarrhoea. We aim to characterise abnormalities in FGF19 in PBAD, in particular the response of the hormone to meal stimuli and to describe phenotypic patterns of response. We have explored possible associations of genetic polymorphisms with both $\mathrm{PBAD}$ and specific phenotypes.

Methods Subjects with PBAD were prospectively recruited. After an overnight fast, blood was sampled every 90 min for $6 \mathrm{~h}$. Meals were provided at 9:00 and 12:00. Serum FGF19 was quantified by ELISA using a commercially available kit. Three phenotypes of meal stimulated FGF19 response are described: 1. Low-low (L-L) all five serum FGF19 levels $<400 \mathrm{pg} / \mathrm{ml}$. 2. Low-high (L-H) sample 1 $400 \mathrm{pg} / \mathrm{ml}$ sample 4 or $5>400 \mathrm{pg} / \mathrm{ml}$. 3. High-high (H-H) samples 1 and 3 or $5>300 \mathrm{pg} / \mathrm{ml}$. In a separate part of the study genomic DNA was extracted from 91 subjects with PBAD and 120 diarrhoea control subjects. Eight SNPs were analysed, two from the FXR gene (rs61755050, rs56163822), two from the FGF19 gene (rs1789170, rs948992) as well as SNPs from the genes for OST $\alpha$, klotho $\beta$, FGFR4 and ASBT (rs939885, rs17618244, rs376618, rs188096). Genotyping was performed using Taqman SNP genotyping assays.

Results 18 subjects underwent serial FGF19 sampling. Seven were defined as $\mathrm{L}-\mathrm{L}$ response, five as $\mathrm{L}-\mathrm{H}$ and four as $\mathrm{H}-\mathrm{H}$. Two subjects did not match criteria for the subtypes. The seven L-L subjects had lower SeHCATs compared with L-H and H-H combined $(\mathrm{p}<0.05)$. Five subjects had SeHCATs of $<5 \%$, all but one were L-L. Overall, subjects with lower SeHCATs had lower FGF19 levels. Area under the curve was lower for those with SeHCAT $<5 \%$ than those above (median $701 \mathrm{pg} / \mathrm{ml}$ h vs $1655 \mathrm{pg} / \mathrm{ml} \mathrm{h} \mathrm{p=0.023).} \mathrm{The} \mathrm{FGF19} \mathrm{level} \mathrm{at}$ $1.5 \mathrm{~h}$ correlated with subjects' SeHCAT ( $\mathrm{r}=0.49, \mathrm{p}=0.04)$. The ASBT SNP was associated with L-L subjects, present in four out of seven $(p<0.05)$. No other significant SNP associations were found within the phenotypes described nor between $\mathrm{PBAD}$ as a whole and diarrhoea controls.

Conclusion Serial FGF19 sampling in PBAD identified three responses to meal stimulus. Most individuals with severe PBAD have L-L response of FGF19, and most of these have a polymorphism in the gene for ASBT. L-H and $\mathrm{H}-\mathrm{H}$ phenotypes are seen in those with higher SeHCATs. The L-H pattern resembles that previously reported in healthy individuals. These patterns may represent a defect in the receptor component of the feedback mechanism for BA synthesis.

Competing interests None declared.

\section{OC-082 26-WEEK EFFICACY AND SAFETY OF ONCE-DAILY ORAL LINACLOTIDE IN PATIENTS WITH IRRITABLE BOWEL SYNDROME WITH CONSTIPATION (IBS-C): A EUROPEAN PERSPECTIVE}

doi:10.1136/gutjnl-2012-302514a.82

${ }^{1} \mathrm{~A} \mathrm{~J}$ Lembo, ${ }^{* 2} \mathrm{~J}$ Fortea, ${ }^{2} \mathrm{C}$ Diaz, ${ }^{2} \mathrm{M}$ Falques, ${ }^{3} \mathrm{~J} \mathrm{Z}$ Shao, ${ }^{3} \mathrm{~B} \mathrm{~J}$ Lavins, ${ }^{4} \mathrm{H}$ A Schneier, ${ }^{3} \mathrm{~J}$ M Johnston. ${ }^{1}$ Beth Israel Deaconess Medical Center, Boston, USA; ${ }^{2}$ Almirall, Barcelona, Spain; ${ }^{3}$ ronwood Pharmaceuticals, Cambridge, UK; ${ }^{4}$ Forest Research Institute, Jersey City, USA

Introduction Linaclotide, a minimally absorbed guanylate cyclase-C receptor agonist, is an investigational drug treatment for IBS-C. As part of the European Medicines Authority submission we evaluated the efficacy and safety of linaclotide $290 \mu \mathrm{g}$, administered once daily for 26 weeks (wks), in a Phase 3 trial of patients with IBS-C.

Methods In a randomised, double-blind, Phase 3 trial, IBS-C patients (modified Rome II criteria) with an overall complete spontaneous bowel movement (CSBM) frequency of $<3 / \mathrm{wk}$, an overall spontaneous bowel movement (SBM) frequency of $\leq 5 /$ wk and an average abdominal pain score of $\geq 3(0-10$ scale) during a $2 \mathrm{wk}$ baseline period were randomised to linaclotide or placebo for $26 \mathrm{wks}$ of treatment. Efficacy parameters were analysed at 12 and 26 wks.

Results In total, 804 patients (female 90\%; median age 44 years) received linaclotide $(n=401)$ or placebo $(n=403)$. During the $2 w k$ baseline period, $87 \%$ had abdominal pain every day (mean score 5.6; 